\title{
COREDIV modelling of JET ILW discharges with different impurity seeding: nitrogen, neon, argon and krypton*
}

\author{
Irena Ivanova-Stanik, \\ Roman Zagórski \\ and JET contributors ${ }^{\&}$
}

\begin{abstract}
Numerical simulations with the COREDIV code of JET H-mode discharges with 25 MW of auxiliary heating in the ITER-like wall (ILW) configuration with different impurity seedings - nitrogen (N), neon (Ne), argon (Ar) and krypton (Kr) - are presented. All simulations have been performed with the same transport model and input discharge parameters like auxiliary heating, volume average plasma density, confinement factor. Only the seeded impurity puff rate was changed in the calculations. It appears that for the considered heating power of $25 \mathrm{MW}$ and relatively low volume electron average density $\left.<n_{\mathrm{e}}\right\rangle=6.2 \times 10^{19} \mathrm{~m}^{-3}$, impurity seeding is necessary. It has been found that for every gas at the maximum level of the seeding rate, allowed by the code convergence, the power to the plate is reduced up to 2-4 MW, with electron temperature at the plate of about $2 \mathrm{eV}$, indicating semi-detached conditions in the divertor region. It should be noted, however, that in cases with low and medium $Z$ impurity ( $\mathrm{N}, \mathrm{Ne}$ and $\mathrm{Ar}$ ), tungsten radiation is a significant part of radiation losses and stays above $22-32 \%$ of the total energy losses, but for high $Z$ impurity (Kr) it is reduced up to $10 \%$ of the total losses. The maximum of the $\mathrm{Kr}$ radiation is between the pedestal region and separatrix, showing that radiative mantle can be created, which might have a strong influence on the plasma parameters in the pedestal region.
\end{abstract}

Keywords: impurity seeding • integrated modelling • tokamak

I. Ivanova-Stanik ${ }^{\bowtie}$, R. Zagórski

Institute of Plasma Physics and Laser Microfusion,

23 Hery Str., 01-497 Warsaw, Poland,

Tel.: +48 22638 1478, Fax: +48 22666 8372,

E-mail: irena.ivanova-stanik@ifpilm.pl

\& See the Appendix of F. Romanelli et al.

Nucl. Fusion, 55(10), 104001 (2015).

DOI: $10.1088 / 00295515 / 55 / 10104001$

Received: 9 June 2016

Accepted: 12 November 2016

\section{Introduction}

The scrape-off layer (SOL) radiation of intrinsic impurities in tokamaks with tungsten (W) as the target plate material is strongly limited. That might lead to high heat fluxes to divertor and corresponding high target plate temperatures, with the consequence of increased W sputtering. However, the reduction of divertor target power loads to an acceptable level is a critical issue for future tokamaks and fusion reactors. The radiative exhaust of energy by externally seeded impurities is considered presently as a promising method of spreading energy over a large wall area and therefore the effect of the impurity seeding on the plasma performance and heat load mitigation have to be understood. This is, in particular, true for JET experiments with the new ITER-like wall (ILW) configuration (ILW: beryllium (Be) wall $+\mathrm{W}$ divertor), which shows that the plasma performance is strongly affected by the presence of tungsten [1]. In particular, experiments have been performed to study the so-called radiative scenarios, where the influence of the seeding impurity on the main plasma parameters is studied [2]. It has been found that

\footnotetext{
*This paper is based on a presentation given at 13th Kudowa Summer School "Towards Fusion Energy", Kudowa Zdrój, Poland, 13-17 June 2016.
} 
seeded impurities can affect the shape of density and temperature profiles, influence the $\mathrm{L}-\mathrm{H}$ power threshold, the pedestal position and parameters as well as the pedestal stability with its direct consequence on plasma performance.

In this paper, numerical simulations with the COREDIV code of JET H-mode discharges in ITER-like wall configuration and with different impurity seedings such as nitrogen $(\mathrm{N})$, neon $(\mathrm{Ne})$, argon $(\mathrm{Ar})$ and krypton $(\mathrm{Kr})$ are presented.

Since the energy balance in tokamaks with metallic walls depends strongly on the coupling between bulk and the SOL plasma integrated modelling approach has to be applied. On the one side, the seeded impurities can reduce the power to the SOL/divertor regions, leading to a reduction of the $\mathrm{W}$ influx, but from the other side, they can increase the $\mathrm{W}$ production due to enhanced sputtering. Therefore, the joint treatment of both regions is necessary, as long as the edge plasma is not separated from the bulk plasma.

The physical model used in the COREDIV is based on a self-consistent coupling of the radial transport in the core to the 2D multi-fluid description of the scrape-off layer. The COREDIV code was successfully benchmarked against a number of JET discharges not only with carbon plates [3], but with tungsten divertor and beryllium wall (JET ILW) for nitrogen [4, 5] and neon [6] seeding, proving its capability of reproducing the main features of JET seeded discharges, as the electron density and temperature profiles, the total radiated power, the effective ion charge $\left(Z_{\mathrm{EFF}}\right)$ and tungsten concentration as well as profiles of radiation.

\section{Model and results}

Simulations are performed for JET discharges with different seeding gases ( $\mathrm{N}, \mathrm{Ne}, \mathrm{Ar}$ and $\mathrm{Kr}$ ) assuming different levels of impurity influx. As a reference scenario, high-power JET shot is chosen (\#87194), which is characterized by the following main parameters: plasma current $I_{p}=2.6 \mathrm{MA}$, toroidal magnetic field $B_{\mathrm{T}}=2.5 \mathrm{~T}$, volume averaged $\left\langle n_{\mathrm{e}}\right\rangle_{\mathrm{VOL}}=6.2$ $\times 10^{19} \mathrm{~m}^{-3}$ and line averaged $\left.<n_{\mathrm{e}}\right\rangle_{\text {LINE }}=6.7 \times$ $10^{19} \mathrm{~m}^{-3}$ electron density, separatrix density $n_{e s}=3.0$ $\times 10^{19} \mathrm{~m}^{-3}, \mathrm{H}$-factor (IPB98 (y,2) [7]) $\mathrm{H}_{98}=0.8$ and auxiliary heating $P_{\text {aux }}=25 \mathrm{MW}$. We observe that it is possible that changes in confinement due to the level of the different gases and to the different radiation patterns are not accounted for in this simulation.

The comparison between experimental and simulated profiles of electron density and electron and ion temperatures is shown in Figs. 1 and 2, respectively.

In order to reproduce the experimental density profile, relatively strong plasma peaking has been assumed $\left(C_{p}=0.3\right)$, where $C_{p}$ is the density peaking coefficient $[8,9]$.

All the simulations are done for the same input parameters, except seeded impurity type and its puffing rate. In case of $\mathrm{N}$ seeding, the recycling coefficient of $R_{\mathrm{I}}=0.25$ is used whereas for $\mathrm{Ne}$, Ar and $\mathrm{Kr}$ the coefficient is $R_{\mathrm{I}}=0.925$, taking into account that nitrogen is not recycling impurity. For radial diffusion in the

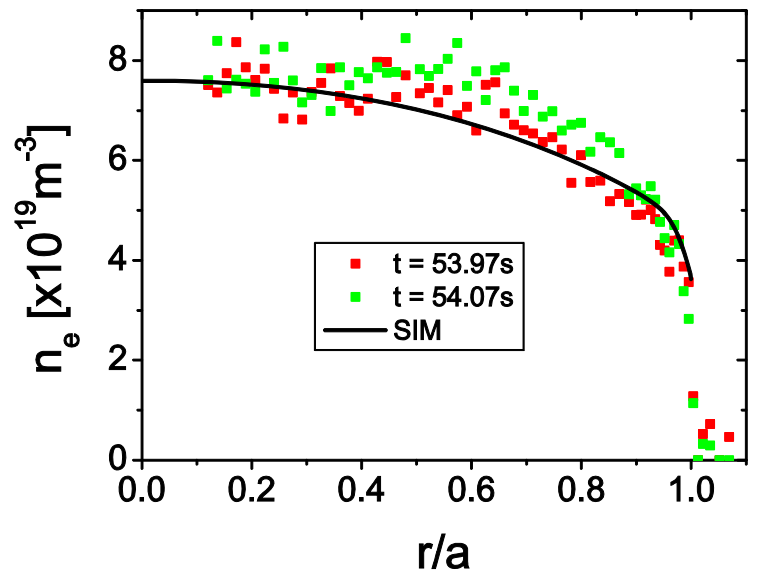

Fig. 1. Density profile by simulation and experiment for shot \#87194 at the time $t \sim 54 \mathrm{~s}$.

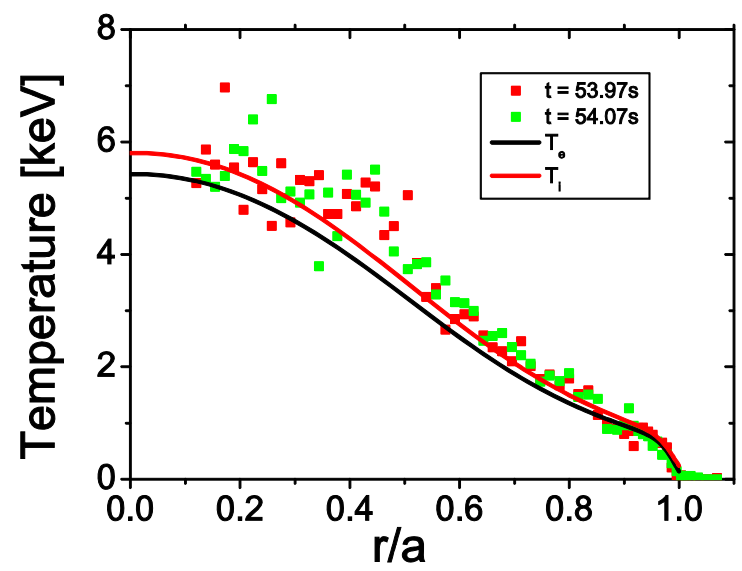

Fig. 2. Ion and electron temperature profile by simulation and experiment for shot \#87194 at the time $t \sim 54 \mathrm{~s}$.

SOL, we use $D_{\perp}^{\text {SOL }}=0.5 \mathrm{~m}^{2} / \mathrm{s}$ whereas for the core transport, only anomalous transport is considered, neglecting contributions from the neoclassical transport.

The main plasma parameters versus impurity influx for different gases $(\mathrm{N}, \mathrm{Ne}, \mathrm{Ar}$ and $\mathrm{Kr}$ ) are presented in Fig. 3. In particular, we show radiation fraction $\left(f_{\mathrm{RAD}}\right)$, power to the SOL $\left(P^{\mathrm{SOL}}\right)$ and to the plate $\left(P^{\mathrm{PLATE}}\right)$, electron temperature at the plate $\left(T_{\mathrm{e}}^{\text {PLATE}}\right)$, SOL radiation $\left(R^{\mathrm{SOL}}\right)$ and effective charge $\left(Z_{\mathrm{EFF}}\right)$. It should be noted that the nitrogen puff level is reduced by a factor of 7 in the figures in order to have better comparison between all impurities. Simulations are performed from a negligible level of the seeding until the maximum value allowed by the numerical code stability and consequently, full detachment is not considered in the simulations.

The threshold power $\left(P_{\mathrm{H}-\mathrm{L}}\right)$, calculated according to the Martin's law [10] is found to be 9.5 MW for the considered JET shot and it can been seen that there is no problem to stay in H-mode for all impurities and seeding levels. However, the power to the plate without impurity seeding (13.5 MW) (see Fig. 3) would be relatively high (exceeding technological heat flux limits $10 \mathrm{MW} / \mathrm{m}^{2}$ and we use that divertor plate surface is $1 \mathrm{~m}^{2}$ ) and impurity seeding is necessary to reduce the power to the target plates for the simulated discharge.

The achieved total radiation fractions are between 70 and 80\%: $71 \%$ for N, $80 \%$ for $\mathrm{Ne}, 76.5 \%$ 

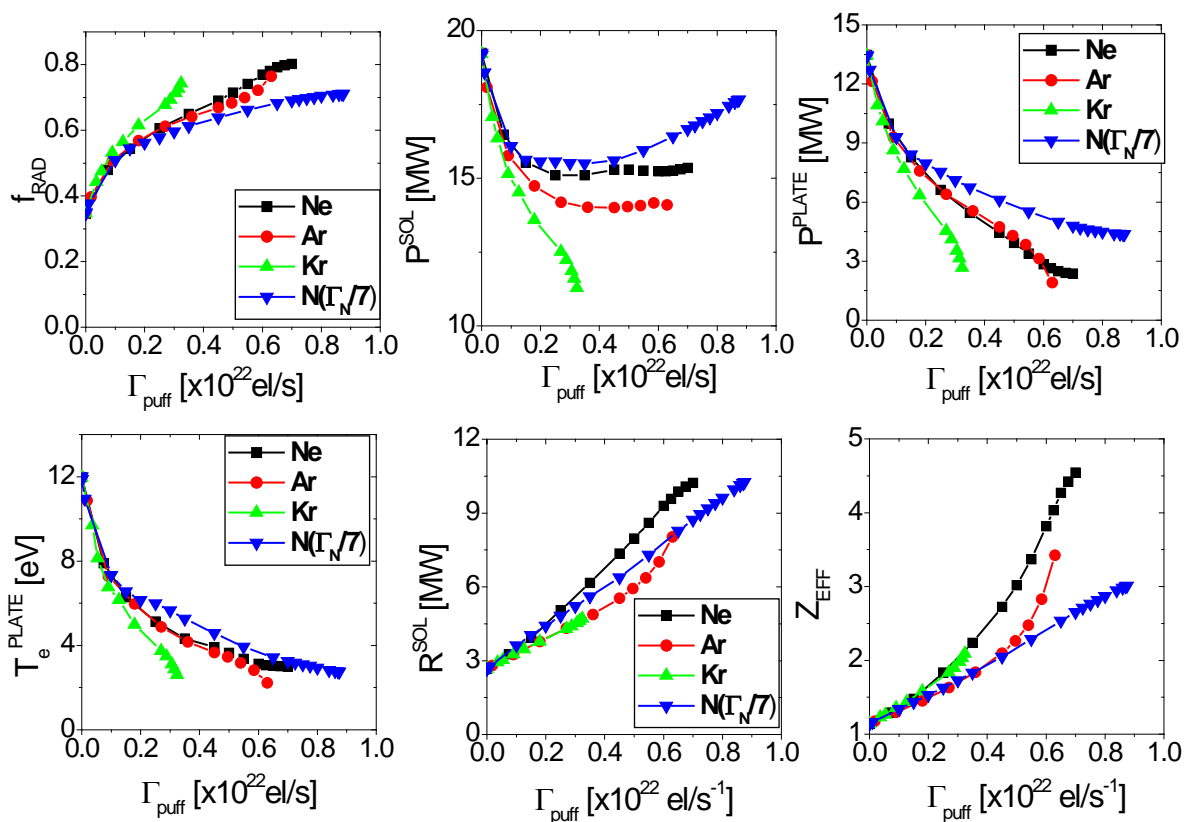

Fig. 3. Main plasma parameters versus impurity influx for different gases ( $\mathrm{N}, \mathrm{Ne}, \mathrm{Ar}$ and $\mathrm{Kr})$ : radiation fraction $\left(f_{\mathrm{RAD}}\right)$, power to the SOL $\left(P^{\mathrm{SOL}}\right)$ and to plate $\left(P^{\mathrm{PLATE}}\right)$, electron temperature at the plate $\left(T_{\mathrm{e}}^{\mathrm{PLATE}}\right)$, SOL radiation $\left(R^{\mathrm{SOL}}\right)$ and effective charge.

for $\mathrm{Ar}$ and $74.5 \%$ for $\mathrm{Kr}$ seeding, respectively. The radiation fraction for low $Z$ impurities $(\mathrm{N}, \mathrm{Ne})$ goes to saturation with the increasing of the seeding rate. It has been found that for every gas at the maximum level of the seeding power to the plate is reduced by 2-5 MW and the electron temperature at the plate is about $2-3 \mathrm{eV}$, indicating semi-detached conditions in the divertor region. In case of $\mathrm{Kr}$ seeding, the reduction of the power to the plate is very sensitive to the seeding level. For puffing levels smaller than $0.3 \times 10^{22} \mathrm{el} / \mathrm{s}$, we observe similar values of $Z_{\mathrm{EFF}} \approx$ $1.8-2$, but for higher puffing rates, there are significant differences in the $Z_{\mathrm{EFF}}$ values. The maximum $Z_{\mathrm{EFF}}$ is obtained for the Ne seeding, which is about two times higher in case of $\mathrm{Kr}$ seeding.
SOL radiation $\left(R^{\mathrm{SOL}}\right)$ increases almost linearly with the seeding level, and the largest radiation is achieved for $\mathrm{N}$ and the smallest for $\mathrm{Kr}$ seeding, depending on the cooling rates of the impurity type. The behaviour of the power to the SOL as a function of the impurity puff rate depends on the impurity type. For Kr, it always decreases with the increase of the seeding level, for $\mathrm{Ne}$ and Ar, saturation is achieved, whereas for $\mathrm{N}$ seeding, increase of $P^{\mathrm{sOL}}$ is seen after initial reduction. Therefore, for nitrogen, large seeding levels are possible in the $\mathrm{H}$-mode.

In Fig. 4 , we present total core radiation, $\mathrm{W}$ radiation in the core $\left(R_{\mathrm{W}}^{\mathrm{CORE}}\right)$, radiation by seeding impurity $\left(R_{\mathrm{IMP}}^{\mathrm{CORE}}\right)$, average ion temperature $\left(<T_{i}>\right)$, tungsten concentration $\left(C_{\mathrm{w}}\right)$ and seeded impurity
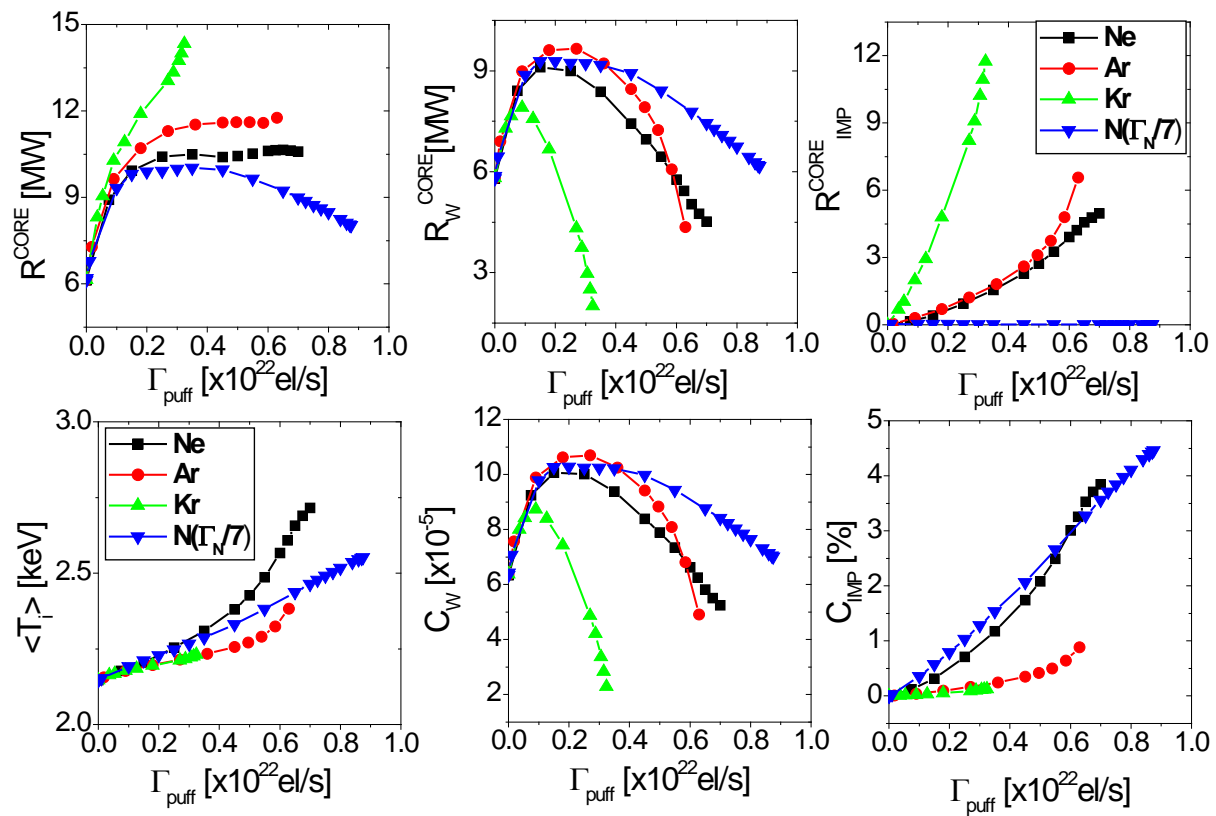

Fig. 4. Main plasma parameters for different impurity puff: $\mathrm{N}, \mathrm{Ne}, \mathrm{Ar}$ and $\mathrm{Kr}$ level: total $\left(R^{\mathrm{CORE}}\right), \mathrm{W}\left(R_{\mathrm{W}}^{\mathrm{CORE}}\right)$ and by seeding impurity $\left(R_{\mathrm{IMP}}^{\mathrm{CORE}}\right)$ radiation in the core, average ion temperature $\left(<T_{i}>\right), \mathrm{W}\left(C_{\mathrm{W}}\right)$ and impurity $\left(C_{\mathrm{IMP}}\right)$ concentration. 


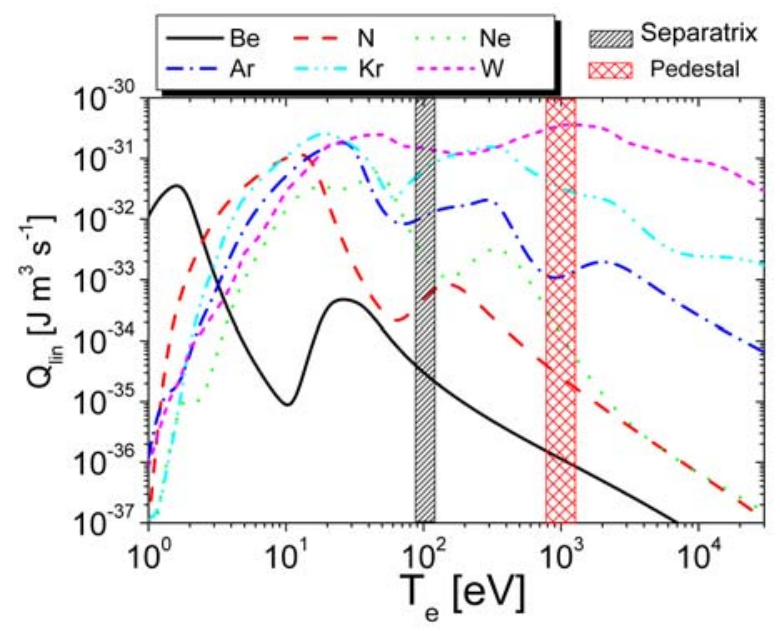

Fig. 5. Cooling rate for $\mathrm{Be}, \mathrm{N}, \mathrm{Ne}, \mathrm{Ar}, \mathrm{Kr}, \mathrm{W}$ in coronal equilibrium.

concentration $\left(C_{\mathrm{IMP}}\right)$ versus impurity puffing level. The maximum seeded impurity radiation in the core is observed for $\mathrm{Kr}$ seeding, with the smallest for nitrogen, which is consistent with our expectations coming from coronal equilibrium (see Fig. 5). For typical core temperatures $\left(T_{\mathrm{e}}>>150 \mathrm{eV}\right)$, the radiation efficiency of $\mathrm{Kr}$ is about 1000 higher than for $\mathrm{N}$.

Only for $\mathrm{Kr}$ seeding, the $\mathrm{W}$ radiation in the core might be fully replaced by $\mathrm{Kr}$ radiation whereas for other impurities the $\mathrm{W}$ radiation in the core remains a significant part of the total radiation losses. For low and medium $Z$ impurities ( $N$, Ne and Ar), tungsten radiation is a significant part of radiation losses and stays above $22-32 \%$ of the total energy losses, but for high $Z$ impurity $(\mathrm{Kr})$, it is reduced down to $10 \%$ of the total losses. Correspondingly, $\mathrm{W}$ concentration for $\mathrm{N}, \mathrm{Ne}, \mathrm{Ar}$ goes down to 5-6 $\times 10^{-5}$ level whereas only for $\mathrm{Kr}$, it is reduced to
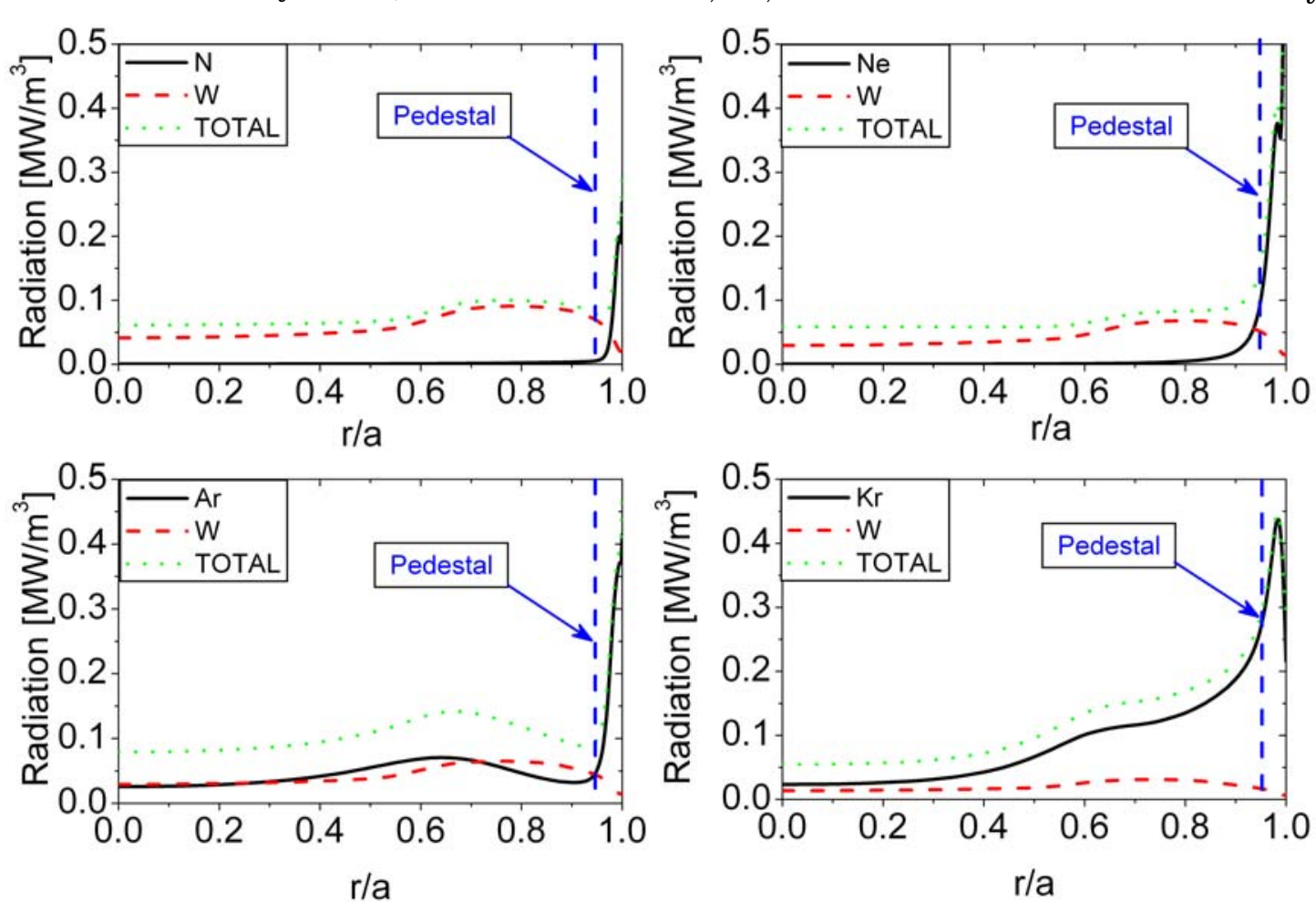

The COREDIV code has been used to simulate JET discharges in the new ITER-like wall configuration. The focus has been put on auxiliary heated $25 \mathrm{MW}$ H-mode discharge with different impurity seeding: $\mathrm{N}, \mathrm{Ne}, \mathrm{Ar}$ and Kr. For the considered auxiliary heatthe plate of about $2-3 \mathrm{eV}$ are achieved, as can be seen in Fig. 3, which corresponds to similar sputtering yield values. However, the total tungsten influx due to sputtering processes is higher for low $Z$ impurities, which is the effect of higher impurity flux to the target plates. At maximum seeding rate, the impurity concentrations range from $4 \%$ for $\mathrm{Ne}$ and $\mathrm{N}$ to $0.1 \%$ for $\mathrm{Kr}$. It can be seen from Fig. 4 that with the increase of the impurity puff level, the average ion temperature increases due to the effect of plasma dilution by impurity ions.

The radiation profiles in the core for different impurities at the maximum impurity seeding level are shown in Fig. 6. As can be seen, radiation in the core by seeded impurities increases with the impurity atomic number, and simultaneously tungsten radiation is reduced. Only for nitrogen, the extrinsic impurity radiation is located close to the separatrix, whereas for other impurities, strong radiation in the pedestal region is observed, which might affect the confinement properties. In addition, for $\mathrm{Ar}$ and $\mathrm{Kr}$, significant part of the radiation is localized in the core. The maximum of the radiation for $\mathrm{N}, \mathrm{Ne}$ and $\mathrm{Ar}$ is at the separatrix, but for $\mathrm{Kr}$, the maximum is between separatrix and pedestal. In the case of $\mathrm{Ar}$ and $\mathrm{Kr}$ seeding, the formation of the radiating belt might be possible.

\section{Conclusion}

Fig. 6. Radiation profiles: total, $\mathrm{W}$ and seeded impurity in the core. The dotted line shows the pedestal position. 
ing and density levels, impurity seeding to reduce the power to the target is required. Sensitivity studies have been done to give insight on the influence of different impurities on main plasma parameters:

- $Z_{\mathrm{EFF}}$ is defined by low- $Z$ impurity level, smaller dilution for the case with $\mathrm{Kr}, Z_{\mathrm{EFF}} \sim 2.2$.

- Only for nitrogen, radiation is localized close to the separatrix.

- Maximum radiation fraction is observed for $\mathrm{Ne}$ $(80 \%)$.

- W radiation decreases with increasing the impurity atomic number.

- For Ar and $\mathrm{Kr}$, significant part of the radiation is localized in the core.

- Only for $\mathrm{Kr}, C_{\mathrm{W}} \sim 2 \times 10^{-5}$, the $\mathrm{W}$ production practically stops.

- Possible pedestal degradation is observed for $\mathrm{Ne}$, Ar and $\mathrm{Kr}$ seeding.

- Possible formation of radiation belt for Ar and $\mathrm{Kr}$ seeding can be seen.

Acknowledgments. This work has been carried out within the framework of the EUROfusion Consortium and has received funding from the Euratom Research and Training Programme 2014-2018 under grant agreement No. 633053. The views and opinions expressed herein do not necessarily reflect those of the European Commission. This scientific work was partly supported by the Polish Ministry of Science and Higher Education within the framework of the scientific financial resources in the year 2016 allocated for the realization of the international co-financed project. Authors would like to thank Dr. R. Dux for the data for krypton.

The 13th edition of the Kudowa Summer School "Towards Fusion Energy", held in Kudowa Zdrój, Poland on 13-17 June 2016, was supported by the Polish Physical Society as well as the Polish Ministry of Science and Higher Education.

\section{References}

1. Baranov, Yu. F., Challis, C. D., Hobirk, J., Baruzzo, M., Hender, T., \& EFDA JET contributors. (2013). Interplay between confinement, impurities and MHD in JET hybrid pulses with ITER like wall. (40th EPS Conference on Plasma Physics, 1-5 July 2013, Espoo, Finland). Europhys. Conf. Abstracts, 37D, P5.142 (4 pp.).

2. Wischmeier, M. (2015). High density operation for reactor-relevant power exhaust. J. Nucl. Mater., 463, 22-29.

3. Zagorski, R., Telesca, G., Arnoux, G., Beurskens, M., Fundamenski, W., McCormick, K., \& JET-EFDA contributors. (2009). Self-consistent modeling of impurity seeded JET advanced tokamak scenarios. J. Nucl. Mater., 390/391, 404-409.

4. Ivanova-Stanik, I., Zagórski, R., Telesca, G., Czarnecka, A., Challis, C., Hobirk, J., \& JET EFDA contributors. (2014). Integrated modelling of nitrogen seeded JET ILW discharges for H-mode and hybrid scenarios. Contrib. Plasma Phys., 54(4/6), 442-447. DOI: $10.1002 /$ ctpp.201410024.

5. Telesca, G., Ivanova-Stanik, I., Zagórski, R., Brezinsek, S., Czarnecka, A., Drewelow, P., Giroud, C., Huber, A., Wiesen, S., Wischmeier, M., \& JET contributors. (2015). Numerical simulations of JET discharges with the ITER-like wall for different nitrogen seeding scenarios. J. Nucl. Mater., 463, 577-581. http://dx.doi.org/10.1016/j.jnucmat.2014.11.024.

6. Zagórski, R., Ivanova-Stanik, I., Czarnecka, A., Telesca, G., Brezinsek, S., \& JET EFDA contributors. (2015). Influence of seeding and SOL transport on plasma parameters in JET ITER-like wall H-mode discharges. J. Nucl. Mater., 463, 649-653. http:// dx.doi.org/10.1016/j.jnucmat.2014.11.024.

7. ITER. (2013, January 7). ITER Physics Guidelines ITER Report. (ITER N 19 FDR 101-07-13 R 0.1). Available from https://fusion.gat.com/iter/iter-fdr/ final-report-sep-2001/Dsgn_Basis_Documents_ (DBDs)/Phys Guidelines.pdf.

8. Zagorski, R., Ivanova-Stanik, R. I., \& Stankiewicz, R. (2013). Simulations with the COREDIV code of DEMO discharges. Nucl. Fusion, 53(7), 073030 (6 pp.).

9. Ivanova-Stanik, I., \& Zagorski, R. (2015). Mitigation of the divertor heat load in DEMO reactor by impurity seeding. J. Nucl. Mater., 463, 596-600.

10. Martin, Y. R., Takizuka, T., \& ITPA CDBM H-mode Threshold Database Working Group. (2008). Power requirement for accessing the H-mode in ITER. J. Phys.Conf. Series, 123(1), 012033. DOI: 10.1088/17426596/123/1/012033. 